Cross, K. W., Hassall, L. \& Gath, D. (1972) Psychiatric day-care: the new chronic population? British Journal of Preventive and Social Medicine, 26, 199-204.

Gath, D. H., Hassall, C. \& Cross, K. W. (1973) Whither psychiatric day-care? A study of day patients in Birmingham. British Medical Journal, 1, 94-98.

Hassall, C., Gath, D. \& Cross, K. W. (1972) Psychiatry day-care in Birmingham. British Journal of Preventive and Social Medicine, 26, 112-120.

JARMAN, B. (1983) Identification of underprivileged areas. British Medical Journal, 286, 1705-1709.

- (1984) Underprivileged areas: validation and distribution of scores. British Medical Journal, 289, 1587-1592.
McCreadie, R. G., Robinson, A. D. \& Wilson, A. O. A. (1984) The Scottish survey of chronic day patients. British Journal of Psychiatry, 145, 626-630.

MCGrath, G. \& TANTAM, D. (1987) Long stay patients in a psychiatric day hospital. A casenote review. British Journal of Psychiatry, 150, 836-840.

PryCE, I. G. (1982) An expanding 'stage army' of long stay psychiatric day patients. British Journal of Psychiatry. 141, 595-601.

Vaughan, P. J. (1983) The disordered development of day care in psychiatry. Health Trends, 15, 91-94.

WILKINSON, G. (1984) Day care for patients with psychiatric disorders. British Medical Journal, 288, 1710-1712.

\title{
A staff group in a burns unit
}

\section{Managing patients' psychological needs}

\author{
D. ANTEBI, Research Registrar, Burden Neurological Hospital, Stapleton, Bristol; and \\ N. R. Ambler, Clinical Psychologist, Glenside Hospital, Stapleton, Bristol
}

The issue of the relationship between physical illness and psychological disorder has a long and chequered history. It is therefore difficult to derive practice implications. However, there are associations between methods of patient care and long-term psychological and physical functioning which have provided some guiding principles (Nichols, 1984). This paper describes how these principles have been applied in a regional burns unit.

Psychological care is often neglected in general hospitals. After illness or trauma, when distress would be expected, it is often either ignored or regarded as disruptive. This distress tends to be left to be managed by those with the most patient contact, i.e. nurses, and yet, they often feel ill-prepared and untrained for this. Furthermore, the ward environment offers little privacy and the predominant emphasis on physical care engenders the feeling of conveyor belt medicine.

The psychological needs of patients in hospitals are wide-ranging and are influenced by a number of factors. These include the ability to cope with stress, event factors such as degree of trauma and environmental factors such as family support. Burns patients are no exception. Added to this, they have to cope with painful treatment procedures, protracted hospital stay and disfigurement. As a group, they are also more likely to have pre-existing problems such as epilepsy, dementia, mental handicap and alcoholism. It is not surprising, therefore, that a one year followup study of severely burned patients revealed that two thirds were suffering persistent psychological problems (White, 1982). The way in which hospital staff manage psychological distress during the early stages of recovery is likely to have implications for patients' longer term adjustment. Awareness of this led the staff of the local adult regional burns unit to get in touch with us to discuss ways in which this aspect of their work could be developed.

We had several meetings with the burns team about how this might be achieved. There already existed a system of referral to the psychiatric service for severe psychological disturbance. However, their request did not concern the small proportion of extreme cases but the issue of general psychological care. We agreed this would be better dealt with by means of a staff group. After discussion, we decided this would run once a week for an hour in a side-room of the 20-bedded burns unit. Rather than set a timetable of topics for discussion, any member of staff could raise any issue or aspect of patient care in the meeting. It was open to any member of the multidisciplinary team to attend but there was no compulsion to do so. We were concerned that these meetings should not serve as an alternative psychiatric service and we therefore made it explicit at the outset that we would not see patients. The structure of the group was necessarily open due to the limitations imposed by the nursing shift system. The declared aim of the group was to raise confidence and awareness in dealing with psychological issues in the unit. During the first three months attendance was variable but this improved to consistently between seven and eleven. 
In the main the meetings would begin with a member of staff raising a specific case which presented difficulties. There would follow a period of free-floating discussion from which we would try to draw together themes. This served both as a method of working on the difficulties of the specific case and as a means of identifying general psychological issues. The subject which most often recurred in the meeting was the perceived breakdown of communication between staff and patients. This was expressed as patient apathy or aggression, constant requests for reassurance or active resistance to treatment. An example was an elderly lady who was excessively demanding and insisted she would not leave hospital alive when, in fact, her burns were healing satisfactorily. For their part, the staff were aware of their own uncertainties in dealing with dilemmas such as how much or how little to inform patients and relatives about expected outcome. Another example was whether or not to explore expressed suicidal feelings with patients. Several of the staff were concerned that to discuss this with a man who had severely burned himself in a suicide attempt might increase the risk of his trying again. Their instinctive approach was to concentrate on whatever they thought might cheer him up. On other occasions the meetings were more didactic in style when the staff introduced topics such as mental handicap, epilepsy and dementia because they felt they needed to become more informed.

Having established these areas of difficulty, we introduced the idea of communication as a skill and concepts such as active listening, reading non-verbal signs, separating process from content in communication and understanding differences in people's styles of coping. It was necessary to spend time developing foundations in these principles as most of the ideas were new. This enabled us to look in more detail at what was going wrong in the examples raised and to explore alternative strategies which they could use.

For most staff in the meeting this was a novel way of approaching patients and it naturally took time to learn the language and concepts involved. This worked both ways. For example, it was initially hard for us to appreciate all that was entailed in "doing a dressing" on a burns unit.

Over the months the content of the meetings changed in the sense that there was a greater level of self-disclosure and increasing willingness to lower the barrier of professionalism in discussing the emotional needs of staff and patients.

Overall it is difficult to evaluate the extent to which the meetings have achieved their original aim, but there are some useful indicators. We circulated a questionnaire to all the staff in the unit to sample their views about the meetings. From the feedback these provided the consensus view was generally favourable. There were also comments on how it had changed their approach to patients and the fact that there was greater cohesion among the staff. As a further indicator they have also produced an information booklet for patients being discharged from the unit, and there are now plans to formally incorporate psychological assessment into nursing assessment. These positive signs are tempered by the fact that there remain a number of the staff who never come to the meetings and this probably reduces the impact of the service.

In spite of our initial decision not to see patients there remained a pressure to do so. This in some ways would have presented a short cut in our gaining credibility in the unit. However, we felt that this would directly contradict the primary function of the meetings, which was to build staff confidence in integrating psychological skills in their daily work. Nevertheless, our acceptance as part of the ward has grown slowly.

There remain two important questions. Firstly, what benefits have there been, if any, for patients? Formal research is the necessary next step to provide an answer to this. Secondly, how much of this work is specific to a burns unit and how much could be applied in any general hospital ward? There are other examples of the integration of psychological work in general hospitals, albeit of differing styles. From our experience many of the issues raised on the burns unit would equally apply elsewhere in the hospital.

In reviewing our experience, we feel the most important aspects of our approach have been as follows. Firstly, to have been as clear as possible about what was being requested. Our aim was the development of the psychological skills of the staff. Had this not been clear then it would have been easy to take on other psychological work in the unit and in effect to have de-skilled the staff. Secondly, to have maintained a degree of flexibility. Had we been rigid about matters such as, say, consistency of attendance, the meetings could not have taken place. Thirdly, to be aware of the existing knowledge base.

Finally, we began from the position of being a little uncertain about the true significance of psychological factors in a burns unit, and how much support is needed there. Throughout this project the prevailing impact on us has been the huge emotional burden which exists in this setting and which staff are expected to bear.

\section{References}

Nichols, K. A. (1984) Psychological Care in Physical Illness. London: Croom Helm.

WhITE, A. C. (1982) Psychiatric study of patients with severe burn injuries. British Medical Journal, 284, 465-467. 